\title{
BUILDING THE ENGINEERING MindSet: DeVELOPING LEADERSHIP AND MANAGEMENT COMPETENCIES IN THE ENGINEERING CURRICULUM
}

\author{
Marnie Jamieson ${ }^{1}$ and John Donald ${ }^{2}$ \\ ${ }^{I}$ Department of Chemical and Materials Engineering, University of Alberta \\ ${ }^{2}$ School of Engineering, University of Guelph \\ Author E-mail: mvjamies@ualberta.ca and jrdonald@uoguelph.ca
}

\begin{abstract}
In this paper we explore building the engineering mindset from the perspective of developing exceptional leadership and management competencies to guide and support the traditional technical competencies that are the primary focus of undergraduate engineering programs. A knowledge base for engineering, science, and design is developed throughout most engineering programs. Math and science are carefully scaffolded from first year engineering to ensure technical competence by graduation. We ask the questions: "How are leadership and management related to engineering work and design?" and "Can we develop a framework to guide the development of leadership and management skills in the engineering curriculum?" We argue leadership and management are integral to the engineering mindset and necessary to address the complex engineering problems society faces. There is discord between the responsibility of the engineer and the decision-making authority for engineering projects. This dissonance often results in engineers being technically accountable for their designs yet lacking the authority to make decisions with respect to the construction, commissioning, and operation of their designs. To address this gap, we suggest leadership and management training be carefully scaffolded in the same manner that technical competence has been stewarded in engineering programs and propose a framework to do so.
\end{abstract}

Keywords: Engineering, Mindsets, Design, Leadership, Management, Programs, Graduate Attributes, Learning, Outcomes, Authority, Responsibility, Accountability

\section{INTRODUCTION}

A mindset is a set of attitudes, beliefs and experiences framing a way of thinking and interpreting information [1]. An Engineering Mindset is built on the core belief that solutions to human problems can be designed within the constraints of science, economics, environment, and safety risk management. If the solution can't be found within the bounds of known technology then research and innovation may provide a path forward. In addition, a mindset is "a proper understanding of a method's use" in context and within constraints [2]. In this paper we explore building the engineering mindset from the perspective of concurrently developing leadership and management skills with core technical and design skills as the engineering skillset during the undergraduate program. Technical competence is developed throughout most engineering programs and is at the core of the identity of an engineer. It is who we are but is not the only item that defines an engineering mindset or engineering practice. To design solutions an engineer must have developed empathy for the people who will either be served by the design or will use the designed object. The engineer must understand what the user values and desires in the system or the object, what is plausible, and how to research and develop the design options. The engineer must understand the context of the design use and the consequences of the use of the design. The engineer will then work with a variety of disciplines to effect the design of the system or the object within sustainability and regulatory constraints. These tasks require a variety of Bloom's cognitive, affective, and psychomotor domain skills including innovation, creativity, evaluation, empathy, and influence.

\subsection{Motivation}

The motivation for this paper is to present a contextual framework to scaffold engineering leadership and management in the undergraduate engineering curriculum while maintaining the technical competence of our graduates. Designing within technical constraints is one aspect of a successful sustainable engineering design. The design must also be operated or marketed within environmental regulations, safety, and economic constraints. The operation must be managed within these sustainability regulations and constraints for the cradle to grave life cycle of the design and preferably support a circular economy. As product development and design operation are typically done in organizations, they require 
ongoing engineering leadership and management grounded in technical competence. Both are at the core of engineering practice and identity. Increasingly, there are calls for engineers to be more actively involved to influence and steward the impacts of technology on society, by contributing in areas such as policy development, politics, and advocacy $[3,4]$.

The administrative and resource burden for teaching engineering design, leadership, and management is high. There is a cost associated with the intensive work required to develop, mentor, and assess engineering students to become engineering leaders, designers, and managers. This cost may be a barrier that reinforces the tendency to maintain less resource intensive instructional methods and focus on fundamentals and engineering science.

\subsection{The Engineering Practice Gap}

Graduating engineers are technically competent, but sometimes lack communication and professional skills fundamental to successful engineering practice $[5,6]$. The need for strong non-technical skills is also identified by the Canadian Engineering Accreditation Board (CEAB) with a majority of the twelve Graduate Attributes focusing on non-technical skills such as communication, team work, ethics and life long learning [7]. Finally, after graduation, there may be dissonance between the responsibility of the engineer and the organizational decision-making authority for engineering projects. This discord may result in engineers being responsible for their design work yet lacking the authority to make decisions with respect to the construction, commissioning, and operation of their designs [8]. This may be compounded by a lack of influence and leadership skill development. To address this disconnect engineering graduates must become comfortable taking leadership roles in implementing and managing the impacts of engineering designs from economic, environmental, and safety perspectives. In addition there is a role for engineers in the public policy and legislative forums with respect to the management and regulation of complex engineered systems. Currently, engineers are underrepresented in Parliament at a time where their skills and knowledge are needed $[3,4]$ to support sustainability.

To prepare engineering graduates to better negotiate the dissonance between responsibility and authority and become more influential in decision-making surrounding complex designs, we suggest leadership and management concepts be delivered as core content. Concurrent development of professional, leadership, and managerial competence to the same degree as technical competence could help close this gap for engineering graduates. Leadership and management can act as a frame for positioning the development of the underlying non- technical Graduate Attributes in a way that maps to engineering professional practice.

Using the engineering practitioner lens instead of the engineering scientist view, we examine the requirements to practice engineering for program graduates. Our key research and development questions are: "How are leadership and management related to engineering work and design?" and "Can we develop a framework to guide the development of leadership and management skills in the engineering curriculum?'

\subsection{Leadership Management Development Matrix}

A Leadership-Management Development Matrix (LMDM) has been developed by the authors to provide a framework for identifying and scaffolding leadership and managerial skills within the engineering curriculum. The LMDM framework considers the leadership levels and expanding spheres of influence of self, team, organization and society based on principles of both Transformational Leadership $[9,10]$ and the skills approach to leadership $[11,12]$. We also relate underlying skills such as communication, self-regulation and empathy to typical organizational roles in engineering practice (e.g., skilled worker, team leader, project manager, organizational leader, societal leader). The lens of a flexible management model [13] is used to frame the shifting societal expectations of organizations.

The proposed LMDM is demonstrated by its application to a typical exercise in an engineering design course. Graduate Attribute indicators are reviewed and then mapped to the underlying skills. Graduate attribute scaffolding in the curriculum and the supporting leadership and management skills are considered in the context of attribute development.

The LMDM is proposed as a mechanism for identifying and assessing non-technical skill progression through the engineering curriculum and relating these skills to engineering practice. Ultimately the authors hope that it can serve as a framework to help engineering programs develop and assess undergraduate curriculum and learning activities that bring the awareness and practice of the non-technical engineering skills to the same level and rigour as technical skills. This will provide engineering graduates with the base skills to become leaders and stewards of technology in society that reaches beyond the technical aspects of their training.

The LMDM was formulated by mapping the development of leadership and management skills to the career arc of engineering work and engineering design. The objective is to support the development of the whole engineer. We hope to facilitate a broader shift to a more wholistic perspective of engineering education. 


\section{LITERATURE REVIEW/BACKGROUND}

\subsection{The Definition of Engineering Work}

Engineering work and oversight are typically completed by professional engineers:

"The "practice of professional engineering" means any act of planning, designing, composing, evaluating, advising, reporting, directing or supervising that requires the application of engineering principles and that concerns the safeguarding of life, health, property, economic interests, the public welfare or the environment, or the managing of any such act. In Canada, a licence is required to practise professional engineering. Engineering is constantly evolving and new areas of practice are always emerging." [14]

Engineering is a self-governing profession and is regulated provincially in Canada. Legally, the Province of Alberta defines the practice of engineering as:

“(i) reporting on, advising on, evaluating, designing, preparing plans and specifications for or directing the construction, technical inspection, maintenance or operation of any structure, work or process

(A) that is aimed at the discovery, development or utilization of matter, materials or energy or in any other way designed for the use and convenience of humans, and

(B) that requires in that reporting, advising, evaluating, designing, preparation or direction the professional application of the principles of mathematics, chemistry, physics or any related applied subject, or

(ii) teaching engineering at a university"

Engineering and Geoscience Professions Act, Section 1, pg. $8[15]$

Examination of this last definition (bold emphasis ours) illuminates the firm connection of science, mathematics, and technical knowledge as the fundamental basis for the engineering design of systems and products to be used by society in part (A). The underlined emphasis in the above definitions illustrates the social nature and context of engineering work. Engineering has typically served the needs and wants of people with an implicit business motivation. Engineering has historically been a blend of the application of specialized scientific knowledge to useful applications with a business aspect [16]. As the structure of engineering work has evolved with globalization there is an increased expectation of collaboration, telecommuting, virtual teams, increased multi disciplinary diverse collaboration and project complexity hence the requirements for professional (and contextual) skills have increased for engineers [17].
"Engineers no longer manage their daily task with plain substance expertise; instead they must be adept at communication, collaboration, networking, feedback provision and reception, teamwork, lifelong learning, and cultural understanding" [18] (p. 123).

Finally this definition in section (i) draws our attention to "directing the construction, technical inspection, maintenance or operation;" in other words, the management of the "structure, work or process;" and by implication, the leadership of the people involved in these tasks. Although the legal definition of what engineering is does not describe the social responsibility of an engineer both APEGA and Engineers Canada are clear that engineering is concerned with "the safeguarding of life, health, property, economic interests, the public welfare or the environment, or the managing of any such act." It is at the core of the profession.

"The Definition has sufficient breadth so that it applies to all phases of engineering endeavour, including feasibility studies, designing or planning, operations, and decommissioning. That is to say, engineering is not only the design, planning, and supervision of construction of a process plant such as a petroleum refinery, but it also includes supervision of the operation, ongoing maintenance, and modifications of such a facility, as well as its eventual decommissioning." [14]

Engineering work clearly requires fundamental scientific knowledge and skills, professional skills, contextual skills, the ability to appropriately select and competently apply those skills in a variety of situations [19].

\subsection{Impact of Engineering Beyond the Technical}

The growing alignment of Engineering Education with Engineering Practice is clearly set out in the CEAB graduate attributes. Canadian Engineering programs are embracing graduate attribute development and honouring a commitment to engineering fundamental knowledge [20], [21]. Technical/scientific background is part of the engineering identity and so is the professional practice component. Even as the graduate attributes are helping to shape engineering education, the engineering community recognizes there are systemic issues that require resolution to address the complex global problems and risks posed by our technological and consumer driven world. The primary goal of the Engineering Change Lab is to deepen our understanding of engineering and to unlock the potential of engineering by taking action to address systemic challenges [11]. The National Council of Deans of Engineering and Applied Sciences (NCDEAS) are focussing on the UN Sustainable development goals and how we will incorporate these goals in engineering programs [22]. The CDIO syllabus model explicitly encompasses technical, cognitive, procedural engineering 
knowledge and skills embedded in personal, professional and interpersonal skill development [23]. Professional and contextual skill development in undergraduate and practicing engineers is widely recognized as a necessity for the interdisciplinary and collaborative work needed for complex system and the product lifecycle design.

\subsection{Leadership-Management Development}

In practice, engineers apply management-leadership spectrum skills, either explicitly or implicitly. Success in the workplace as an individual contributor is often dependent on technical competence and managerial skills. Further progression requires leadership skills and abilities [10]. Historically, leadership was viewed as a "linear progression from great management performance, but in fact, it is a new course of study"[10]. The skills required to manage tasks and work within managerial systems are somewhat different from those required to lead people to accomplish tasks within a system.

Several management and leadership development frameworks are available to position the scaffolding of personal and professional skills within the engineering curriculum. For example, Transformational leadership [9] identifies how leaders can engage followers to reach high levels of motivation, morality and performance often with change to a new paradigm as an end objective. The skills approach to leadership [11] and the capability model of leadership [12] identify specific skills and/or knowledge required for leadership. Katz [11] categorizes the skills from a technical, human, and conceptual perspective where technical and management skills are viewed as more important early in a career; while the importance of conceptual skills increases as responsibility increases and human skills maintain their importance across domains. The skills and capability models focus on developmental needs to make effective leadership possible rather than on leadership behaviour. The skill category descriptions for both models are similar. Mumford et al. characterize the underlying individual abilities supporting leadership skill development as: motivation, personality, and cognitive ability. Mumford categorizes leadership competencies as:

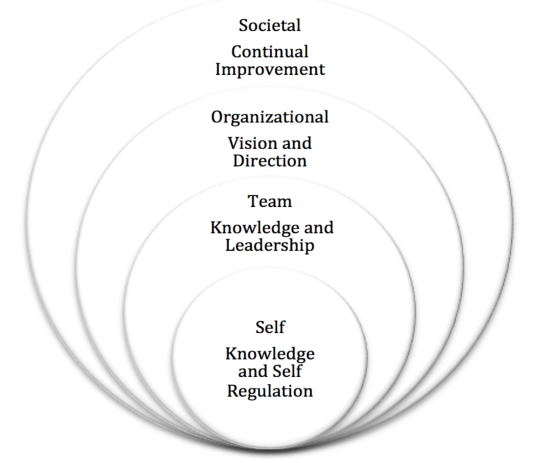

Figure. 1. Leadership Domains of Influence knowledge skills (technical), problem solving skills (conceptual), and social judgement skills (human) [12]. The knowledge category includes the facts and the organizational structure or the expert schema suggesting technical skills are not less important but rather they have been used to an extent as to develop expertise. The manner in which this expertise is utilized may shift [24]. In the transformational leadership model [10], leadership and management skills are identified and both are required to shift an organization or a team to a new way of thinking and doing. Hacker \& Roberts [10] identify creativity, vision, empowerment, and community building as the leadership characteristics required for break through change. The management characteristics are identified as performance, analytical, energetic, and administrative. This describes how transformational leaders (and managers) apply their developed skills and knowledge to effect change in their domain of influence.

Common to many leadership models, including the capabilities and transformational models, is the idea that leadership starts with a need to understand and manage your own knowledge and skills and then grow to be able to lead and manage at larger scales of influence. For our LMDM we represent this increasing circle of leadership influence as "Domains of Influence", from self, through team, to organization, and to society as illustrated in Figure 1. These models and concepts form the framework for leadership activity development in the engineering curriculum. In the proposed LMDM, the skills required for self-leadership and followership are a foundation for the skills required for team leadership, organizational leadership, and societal leadership.

The management model is based on Birkinshaw's [22, 23] continuum of traditional and alternative principles illustrated in Figure 2. Historically organizations were formed for an industrial or business purpose and often resemble the characteristics on the left side of the continuum yet the societal expectations of organizations are shifting towards the right hand side of the continuum. Societal expectations initially shifted from economic growth to sustainable development and more recently, they are shifting towards a socially responsible model

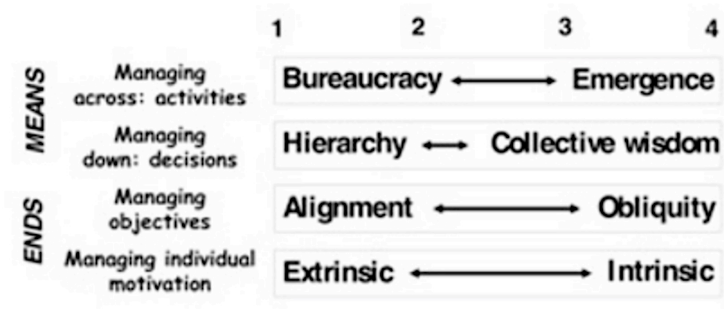

Figure 2. Management Model Framework (Birkinshaw [13]) https://creativecommons.org/licenses/by-nc-sa/3.0/ Used with attribution and no changes. 
with respect for all human needs reflecting the UN sustainable development goals. Birkinshaw's management model framework best captures this tension. It also informs the framework for developing learning activities directed at addressing this shift and supporting skill development for engineering work in the future.

\section{METHOD: LMDM DEVELOPMENT}

Organizations within society exist for a purpose and they exist in a wide variety of sizes. Their purpose may be to govern, to regulate, to do business, to influence, to educate, to protect, to serve or to care for people. Management is what humans do to plan and coordinate tasks to achieve objectives within constraints. This may be in the context of self or organizational management. One can manage the self, a team, a business unit, a collection of units, an organization, or a collection of organizations. Inter-organizational cooperative resource management, legislative, regulatory framework, and policy management are examples of societal objective management. As in leadership, the management skills required for self-management and individual performance form the foundation for the skills required to manage larger organizational units.

The literature review captures the importance of leadership and management skills and the need for engineers to master these non-technical skills to be effective in driving change towards sustainable solutions to complex engineering problems. Figure 3 captures some of the specific characteristics and nature of these leadership and management skills, indicating the overlapping character of both.

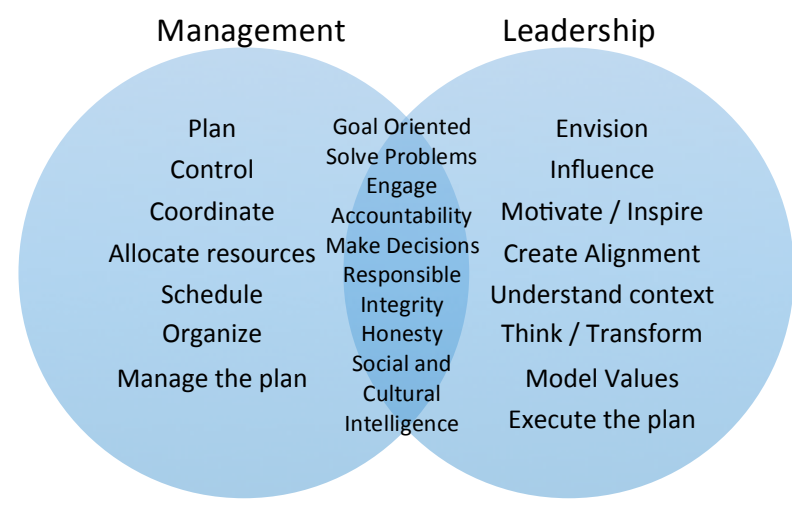

Figure 3. Management Leadership Development Skills Venn Diagram

The societal call for a paradigm shift in the design and management of engineering systems towards a more sustainable reality informed the leadership and management model selection. In turn, these models influenced the skills, roles, and finally the engineering mindset to be developed in a university program. To create the LMDM, we first considered the required skills and developmental levels for an engineer over the course of a career beginning with individual contribution. Next we examined the team, organization, and societal levels and began to identify relevant management and leadership skills for an individual to execute the role in the context of sustainable engineering leadership and management of complex designs and systems. Last we considered the related graduate attribute foundation for each development level, and the progression of the skill development through each of the levels. We assumed a graduating engineer requires an applied competence in the full complement of CEAB graduate attributes.

To position the development of leadership and management skills within the undergraduate engineering curriculum to support a societal transition to sustainable design and development, a change in how engineers steward technology at the organizational and societal levels is required. To this end, we have incorporated the concepts of transformational leadership [9], the skills/ capability approach [12] and the management model framework [25] to create a Leadership-Management Development Matrix (LMDM). The LMDM, shown in Table 1, represents leadership development at the four progressive domains of influence from self, through team, to organization, and finally, to society. At each level, the matrix is aligned with a typical positional management role that can be associated with a leadership development level. Progressive organizational roles encompass and build upon the foundational skill domains of prior roles.

In addition to leadership and management skills, we felt it important to articulate skills in both the cognitive and the affective (behavioral) domains. Developing cognitive and affective regulation (metacognition) underlies the development of leadership and management skill and ability. For each leadership level and corresponding management role, the LMDM describes the nature of each of the four relevant non-technical skill domains: namely cognition, behavior, management, and leadership. This can aid our understanding of how we might scaffold non-technical skills in the curriculum as they relate to the career arc leadership and management development of engineers. For each of the leadershipmanagement development levels, we can identify skills, the skill level required, and relate these to the Graduate Attributes set out by accrediting bodies. The LMDM also identifies the timing (years) within the undergraduate curriculum where the skills could be typically developed and applied. Two dimensions that underlie the LMDM are: one, the program level outcome requirements, which can be represented by the $12 \mathrm{CEAB}$ graduate attributes [7]; and two, the depth and complexity of the of the learning content level, which can be represented by the CEAB definitions of introduced (I), developed (D), and 
Table 1 - Leadership-Management Development Matrix (LMDM)

\begin{tabular}{|c|c|c|c|}
\hline $\begin{array}{l}\text { Leadership } \\
\text { Development } \\
\text { Level (Domain } \\
\text { of Influence) }\end{array}$ & $\begin{array}{l}\text { Management } \\
\text { (Positional) } \\
\text { Level }\end{array}$ & $\begin{array}{l}\text { Non-technical Skill Domains } \\
\text { (1. Cognition 2. Behaviour 3. Management 4. Leadership) }\end{array}$ & Skills \\
\hline $\begin{array}{l}\text { Society } \\
\text { GA: } 1-12(A) \\
\text { Years } 4 \text { to } 5\end{array}$ & $\begin{array}{l}\text { Thought } \\
\text { Leader } \\
\text { Inter } \\
\text { Organization } \\
\text { Manager } \\
\text { Regulatory or } \\
\text { Governing } \\
\text { Body Director }\end{array}$ & $\begin{array}{l}\text { Role: Thought Leader/Inter Org, Manager/Director } \\
\text { 1. Integrative/ Interdisciplinary/Cultural cognitive processing (i.e. } \\
\text { complex design processes or broad management interactions) } \\
\text { a. Code/ standard development (collective experience/cognition) } \\
\text { 2. Inter-organizational network relational-regulation/Social } \\
\text { Intelligence (even more distant)/Cultural intelligence (broadly } \\
\text { defined - both disciplinary and societal) } \\
\text { 3. National and international policy development, environmental, } \\
\text { safety, educational management. Across society and } \\
\text { organizations. } \\
\text { 4. Societal Leadership (Values, economics, freedom, education, } \\
\text { individual vs collective) }\end{array}$ & $\begin{array}{l}\text { Creativity /Vision } \\
\text { Creating value - } \\
\text { insight } \\
\text { Community Builder } \\
\text { Management and } \\
\text { leadership (self }+ \text { ) } \\
\text { Listening skills } \\
\text { Empathy } \\
\text { Metacognitive } \\
\text { skills, } \\
\text { Self-regulation }\end{array}$ \\
\hline $\begin{array}{l}\text { Organization } \\
(\mathrm{n}>20) \\
\text { GA: } 1-12 \text { (A) } \\
\text { Years } 3 \text { to } 4\end{array}$ & $\begin{array}{l}\mathrm{CxO} \\
\text { Dept. Manager }\end{array}$ & $\begin{array}{l}\text { Role: } \mathrm{CxO} / \mathrm{Org} \text {. Manager } \\
\text { 1. Integrative/ Interdisciplinary cognitive processing (e.g. } \\
\text { complex design, procurement, and operational processes } \\
\text { including interdepartmental management) } \\
\text { 2. Interdepartmental network relational-regulation/Social } \\
\text { Intelligence (more distant) } \\
\text { 3. Business integration with societal demands and expectations, } \\
\text { client management, Project, Process-management } \\
\text { 4. Organizational Leadership (vision, mission, values) }\end{array}$ & $\begin{array}{l}\text { Same as above } \\
\text { Contextual } \\
\text { differences with } \\
\text { similar skills sets in } \\
\text { problem solving, } \\
\text { social judgment, and } \\
\text { knowledge schema } \\
\text { categories }\end{array}$ \\
\hline $\begin{array}{l}\text { Team }(\mathrm{n}<20, \\
\text { typical } 5) \\
\text { GA: } 1-12(\mathrm{D}) \\
\text { Years } 2 \text { to } 4\end{array}$ & $\begin{array}{l}\text { Team Leader } \\
\text { Project } \\
\text { Manager }\end{array}$ & $\begin{array}{l}\text { Role: Team Leader } \\
\text { 1. Group cognitive processing (e.g. design processes) } \\
\text { 2. Relational-regulation/Social Intelligence (adaptive ways of } \\
\text { management within relationship) } \\
\text { 3. Team-management, inter team collaboration management, } \\
\text { resources, schedule, etc. } \\
\text { 4. Team leadership (vision, mission, values). Organizational } \\
\text { alignment (vision, mission, values, priorities) } \\
\text { Note: As the domain of influence expands foundational skills } \\
\text { continue to develop and are more deeply explored and applied. } \\
\text { Hence the I, D, A labeling with the role progression. }\end{array}$ & $\begin{array}{l}\text { Connections and } \\
\text { problem solving-- } \\
\text { with others and } \\
\text { ideas. } \\
\text { Administration } \\
\text { Leadership } \\
\text { Listening skills } \\
\text { Empathy } \\
\text { Metacognitive skills } \\
\text { (performer) } \\
\text { Self-regulation }\end{array}$ \\
\hline $\begin{array}{l}\text { Self }(n=1) \\
\text { GA: } 1-12(\mathrm{I}) \\
\text { Years } 1 \text { to } 2\end{array}$ & $\begin{array}{l}\text { Individual } \\
\text { Contributor }\end{array}$ & $\begin{array}{ll}\text { Role: } & \text { Individual (Follower, self leader, self manager) } \\
\text { 1. } & \text { Metacognition (think, transfer knowledge to other domains) } \\
\text { 2. } & \text { Self-regulation/ Emotional Intelligence (behave as individual) } \\
\text { 3. } & \text { Self-management (goals, plans, actions, tasks) } \\
\text { 4. } & \text { Self-leadership (vision, mission, values). Adoption of team } \\
& \text { schedule, goals, vision mission and values } \\
\end{array}$ & $\begin{array}{l}\text { Metacognitive skills } \\
\text { (performer), } \\
\text { Self-regulation } \\
\text { Technical analytical } \\
\text { competency } \\
\text { Ability to learn }\end{array}$ \\
\hline
\end{tabular}

Graduate Attribute List:

1. A knowledge base for engineering

2. Problem analysis

3. Investigation

4. Design

5. Use of engineering tools

6. Individual and teamwork

applied (A) [19]. At the introductory level students begin to learn and apply concepts. At the developing level, students "begin to probe more deeply... and deepen their exploration into concepts." At this level, students realize there is complexity, different levels of organization, and analysis. At the applied level, students are developing insights and working with the knowledge in a very
7. Communication skills

8. Professionalism

9. Impact of engineering on society and environment

10. Ethics and equity

11. Economics and project management

12. Life-long learning

different way. They "explore deeply... and experience controversies, debate and uncertainties...An advanced student can be expected to relate material contextually, to synthesize, integrate and achieve fresh insights. " [26]

All twelve graduate attributes, both technical and nontechnical, influence the engineering leadership and 
management competencies in all leadership domains and management roles for engineering work. At the self and team leadership development levels, the emphasis is toward the technical attributes, communication, and teamwork. Technical skills are important in a leader early on to establish technical credibility with ones peer group and followers. Progressing to the organizational and societal leadership development levels, the emphasis shifts more to graduate attributes 6 through 12 and increased emphasis on contextual aspects. Although the relative importance shifts, technical competence is still necessary for engineering leadership and management. In addition, some technical attributes such as problem analysis will expand to include other models or frameworks of analysis outside of the traditional engineering approach. Similarly, student competence development within the curriculum, from I through D to A, will generally follow progressive spheres of leadership influence and complexity from self to society in the life long learning context. Student exploration depth increases and then transitions to ongoing professional development.

\section{RESULTS: APPLICATION IN THE ENGINEERING CURRICULUM}

The LMDM presented in Table 1 can be used as a framework for engineering faculty and educational developers to explicitly map non-technical skills into the engineering curriculum in a way that relates engineering leadership and management practice from an introductory application of self through to applied applications in society. This parallel positioning of technical and nontechnical skill development meaningful to engineering practice addresses a disconnected view that non-technical graduate attributes and skills are something apart from fundamentals or engineering science.

Utilizing the LMDM in developing engineering curriculum repositions the approach to developing nontechnical graduate attributes. Instead of starting with the graduate attribute in isolation, the attribute and skill level can be contextually positioned within the need for engineering leadership and management in engineering practice. This repositioning can aid instructors when thinking about professional GA development in technical courses, potentially facilitating a move beyond the assignment of isolated problem sets into multifaceted learning activities such as case studies. It also strengthens the positioning of the activities within design courses in a way that can be explicitly related to practice (i.e., you are not just improving your communication skills, you are improving your ability to lead and manage in practice).

As an illustrative example, most engineering programs have design courses where students must work in teams on open ended projects delivering the results of their design and evaluation work as final reports, presentations and/or poster sessions. In these presentations, the assessment of the work is often done with rubrics that are positioned in the context of CEAB graduate attributes. For example, "Cohesiveness of Team" could be related to GA 6 - Individual \& Team Work skills; and the dialogue during the presentation could be related to GA 7 Communication skills. Rubrics for these skills tend to stand alone from the actual framing within engineering practice. For example, a strong performance in the team aspect might be phrased "All members contributed to the presentation and Q\&A session;" and a strong performance in Communication might be phrased as "Clear, complete, thoughtful order to presentation;" and/or "Formulates thorough concluding statements in the context of the problem and design." While these statements may provide information for evaluation and GA assessment, the connection to the broader picture of engineering practice can be lost. Looking to the LMDM framework, an instructor can position these non-technical elements within practice. For example, if the final report is presented in the context of a report to a supervisor, the communication skills assessment could sit within the Team/Project Manager Leadership-Management Domain; whereas if positioned as a presentation to a client, it might fit within the Organizational/ Department Manager leadership-management domain; and a presentation session to stakeholders and professional members might be classified in the societal leadership/management domain. Providing practice context gives the exercise relevance beyond the rubric focus on an independent graduate attribute and moves to the realm of practical experience. Positioning relative to the LMDM also provides a mechanism for instructors and educational developers to think more intentionally about the educational outcomes relative to professional practice.

This is a simple example, but our goal is to enrich engineering education with a supportive method for intentional scaffolding of the contextual and professional aspects of engineering practice into the engineering curriculum. Used across a program, the LMDM could help to identify gaps in practical experiences and enable better planning for student development ahead of the capstone design courses while supporting a more wholistic approach. An approach that supports the transformation of the engineering program to one that enables engineering practice and empowers students to develop a sustainable engineering mindset and skillset with the ability to steward technology sustainability at the personal, team, organizational, societal and global levels.

\section{CONCLUSIONS AND FUTURE WORK}

As the impact of engineering and business on society and our world continues to escalate, there are calls for the engineering profession to increase its focus on technology 
stewardship and to drive sustainable solutions. Also, calls to increase engineering influence beyond the technical to transform our economies with sustainable solutions. Engineering education will need to transform to empower sustainability and build both mindset and skillset capacity in graduating engineers to address current and future demands. Consequently, it is equally important to capture the non-technical skills in the curriculum and value them in parallel with technical skills. This can be challenging, as the direct connection of technical engineering skills to engineering research and practice is readily apparent to faculty and students. Not so apparent, is how the requisite non-technical skills connect to the curriculum beyond design courses.

A Leadership-Management Development Matrix has been created to help both faculty and students envision how the non-technical skills are also foundational to professional practice. By relating the non-technical skills to engineering practice through the lens of leadership and management, the LMDM attempts to position these skills in a way that encourages learning activities in the context of engineering practice and its impact on society. The scaffold follows the leadership-management trajectories that flow from responsibilities to self, to team, to organization, and to society. Beyond the leadership and management components, the LMDM can be grounded in assessment through the CEAB graduate attributes. A simple example has been provided to demonstrate the application of the model.

This work represents a preliminary view of how to position the relevance of non-technical skills in a way that integrates its relevance within the leadership and management domains of engineering practice. In future work we plan to map the leadership management skills more explicitly and provide further examples of how the LMDM can help engineering educators develop whole engineers who bring skills beyond the technical to engineering practice and consequently the development and stewardship of sustainable engineering solutions.

\section{Acknowledgements}

This work was inspired by interaction with many engineering educators at the Canadian Engineering Education Association Conferences and in particular, those that have participated in the National Initiative on Capacity Building and Knowledge Creation for Engineering Leadership (NICKEL) conferences from 2016 through 2019. The authors would like to thank individuals who shared workshop materials and other resources related to the development of the whole engineer. These experiences, along with our engineering teaching, research, and practice experience have all formed and contributed to our thinking.

\section{References}

[1] L. Bosman and S. Fernhaber, Teaching the Entrepreneurial Mindset to Engineers. Cham: Springer, 2018.

[2] M. M. Andreasen, C.T. Hansen, and P. Cash, Conceptual Design Interpretations, Mindset and Models. Cham: Springer, 2015.
[3] H. Brown and B. Keidan, "ONTARIO ENGINEERS FIND THEIR PLACE IN THE HOUSE OF COMMONS," Engineering Dimensions, no. 5, p. 33, 2015.

[4] T. Duever, "Ryerson University holds inaugural engineering conference," Construction Canada, p. NEWS, 31-Mar-2015.

[5] K. Smith, "A Classroom Experience That Builds the Top Skills Employers Want," Manag. Teach. Rev., vol. 1, no. 2, pp. 73-78, 2016, doi: 10.1177/2379298116633870.

[6] C. Kivunja, "Teaching students to learn and to work well with 21 st century skills: Unpacking the career and life skills domain of the new learning paradigm," Int. J. High. Educ., vol. 4, no. 1, pp. 4-11, 2015, doi: 10.5430/ijhe.v4n1p1.

[7] "2019 Accreditation Criteria and Procedures," Nov. 2019.

[8] P. A. Vesilind, Engineering Peace and Justice The Responsibility of Engineers to Society. Cham: Springer, 2010.

[9] J. M.Burns, Leadership, $1^{\text {st }}$ ed. New York: Harper \& Row, 1978.

[10] S. Hacker and T. Roberts, Transformational Leadership: Creating Organizations of Meaning. Milwaukee, Wisconsin: ASQ Quality Press, 2003.

[11] R. L. Katz, "Skills of an effective administrator," Harv. Bus. Rev., vol. 33, no. 1, pp. 33-42, 1955.

[12] M. D. Mumford, S. J. Zaccaro, F. D. Harding, T. O. Jacobs, and E. A. Fleishman, "Leadership skills for a changing world: Solving complex social problems.," Leadersh. Q., (11), no. 1, pp. 12-23, 2000.

[13] J. M. Birkinshaw, What is your Management Model?, 02-Sep2010.: https://www.managementexchange.com/blog/what-yourmanagement-model.

[14] Engineers Canada, "Public guideline on the practice of engineering in Canada | Engineers Canada," Engineers Canada, Feb-2012.: https://engineerscanada.ca/publications/publicguideline-on-the-practice-of-engineering-in-canada..

[15] Engineering and Geoscience Professions Act, "Engineering and Geoscience Professions Act. (2015). Section 1, p. 8." Queen's Printer, 2015.

[16] P. Meiksins, "The 'Revolt of the Engineers' Reconsidered," Technol. Cult., vol. 29, no. 2, pp. 219-246, 1988, doi: $10.2307 / 3105524$

[17] F. F. Joyner, D. T. Y. Mann, and T. Harris, "Engineering as a social activity: Preparing engineers to thrive in the changing world of work.," Am. J. Eng. Educ., vol. 3, no. 1, pp. 67-81, 2012.

[18] p. Lappalainen, "Communication as part of the engineering skill set.," Uropean J. Eng. Educ., vol. 34, no. 2, pp. 123-129, 2009.

[19] M. V. Jamieson and J. M. Shaw, "Teaching engineering for a changing landscape," Can. J. Chem. Eng., vol. 97, no. 11, pp. 2870-2875, 2019, doi: https://doi.org/10.1002/cjce.23626.

[20] A. Parker, E. Watson, M. Ivey, and J. P. Carey, "Approaches to graduate attributes and continual improvement processes in faculties of engineering across Canada: A narrative review of the literature," in Proc. 2019 Canadian Engineering Education Association (CEEA-ACEG19) Conference, Ottawa, ON, 2019.

[21] J. Kaup and B. Frank, "EGAD National Snapshot Survey: Change Progress and Improvement," in Proc. 2016 Can Eng Education Association (CEEA16) Conf., Dalhousie, NS, 2016.

[22] M. Wells, "Realizing the potential of Canadian engineers to change the world | The Star," 2019. [Online]. Available: https://www.thestar.com/opinion/contributors/2019/12/31/realizing-thepotential-of-canadian-engineers-to-change-the-world.html?

[23] E. F. Crawley, J. Malmqvist, S. Östlund, D. R. Brodeur, and K. Edström, Rethinking Engineering Education - The CDIO Approach. Cham: Springer International Publishing, 2014.

[24] P. G. Northouse, Leadership Theory and Practice Ch 3 Skills Approach, 8th ed. Sage, 2018.

[25] J. M. Birkinshaw, Becoming a better boss: why good management is so difficult. San Francisco, CA: Jossey-Bass, A Wiley Brand, 2013, 2013.

[26] Canadian Engineering Accreditation Board, "A Guide to Outcomes-based Criteria: for Visiting Team-Chairs and Program Visitors, version 1.25." Engineers Canada, 01-Mar-2015. 